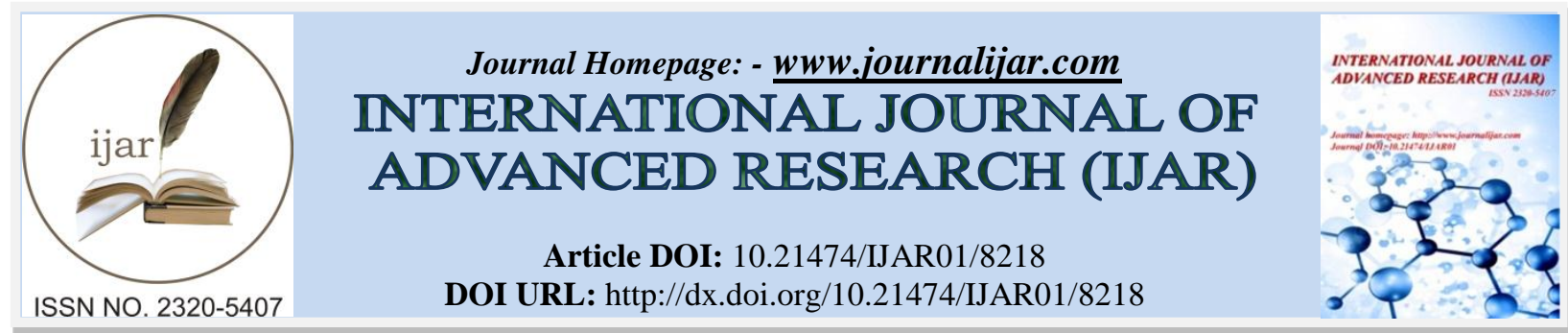

RESEARCH ARTICLE

\title{
A STUDY OF THE EFFECTS OF DIFFERENT DOSES OF SILYMARIN ON ROTENONE-INDUCED RAT MODEL OF PARKINSONISM.
}

\author{
Yasmeen Mohamed El-Harty, Rizk Mahmoud El-Khouly, Hala Fouad El-Baradey and Ahmed El-Sayed \\ Abdelfattah. \\ Department of medical physiology, Faculty of Medicine, Tanta University, Egypt.
}

\section{Manuscript Info}

Manuscript History

Received: 16 October 2018

Final Accepted: 18 November 2018

Published: December 2018

Keywords:

Silymarin, Parkinsonism, Rotenone, BDNF, Dopamine, Substantia Nigra.

\section{Abstract}

Aim of the work: This work was performed to study the effect of different doses of silymarin on rotenone-induced Parkinsonism in rats. Methods: 60 rats divided into 3 groups, I- control group (10 rats) received no treatment, II- Positive control group (10 rats) received intraperitoneal injection of silymarin (SM) at a dose of $200 \mathrm{mg} / \mathrm{kg}$ daily for 2 weeks, III- Rotenone-treated (RT) group (40 rats) received subcutaneous injection of rotenone at a dose of $1.5 \mathrm{mg} / \mathrm{kg} / 48 \mathrm{~h}$ for 12 days, then subjected to preliminary behavioral tests. Rats with parkinsonian features were divided into 4 groups (10 rats each), (IIIaRT group), (IIIb- $100 \mathrm{mg} / \mathrm{Kg}$ SM-RT), (IIIc- $200 \mathrm{mg} / \mathrm{Kg} \mathrm{SM-RT)} \mathrm{and}$ (IIId- $300 \mathrm{mg} / \mathrm{Kg} \mathrm{SM-RT)}$ which received 100, 200, $300 \mathrm{mg} / \mathrm{kg}$ intraperitoneal silymarin daily for 2 weeks.

Results: Rotenone injection caused significant increase of descent latency time in bar test, brain tissue homogenate levels of malondialdehyde, nitrite/nitrate, tumor necrosis factor-alpha, caspase-3 and serum 8-hydroxy-2'-deoxyguanosine and significant decrease of forepaw stride length, brain tissue homogenate levels of catalase, brainderived neurotrophic factor and dopamine when compared to control groups. Silymarin treatment reversed rotenone effect significantly in a dose-dependent manner.

Conclusion: Silymarin can be used as a promising adjuvant therapy in treatment of Parkinsonism. Its neuroprotective effect is mediated by silymarin's antioxidant, anti-inflammatory and anti-apoptotic effect which eventually enhanced dopamine level and the characteristic motor deficits of PD in a dose-dependent manner. Further clinical trials are required with special reference to the dose.

Copy Right, IJAR, 2018,. All rights reserved.

\section{Introduction:-}

Parkinsonism (PD) is now the world's second most common neurodegenerative disorder, affecting more than six million people worldwide (Robert et al., 2018). The initial description of PD, made by James Parkinson in 1817 , mainly focused on akinesia, tremors, and rigidity as the three cardinal motor symptoms of Parkinson's disease (PD). Onset of motor symptoms predominantly results from $50-80 \%$ reduced striatal dopamine levels (Müller \& Möhr, 2018).

Corresponding Author:-Yasmeen Mohamed El-Harty.

Address:-Department of medical physiology, Faculty of Medicine, Tanta University, Egypt. 
Rotenone, a natural cytotoxic compound extracted from plants in the Leguminosae family and one of the most toxic rotenoids, is neurotoxin that has been widely used to mimic PD cellular characteristics since it is a mitochondrial complex I inhibitor. Mitochondrial function impairment, together with other key molecular events, such as oxidative stress and apoptosis, may contribute to the onset of neuronal death and thus, to the symptoms of neurodegenerative diseases (Serrano-García et al., 2018).

L-dopa, which is currently used as the most convenient treatment for PD, is most effective for amelioration of impaired motor behavior in PD patients. On the other hand, too high L-dopa dosing may contribute to neuronal dying and aging process in general (Müller \& Kohlhepp, 2016). This consequently lead to the emergence of levodopa-induced dyskinesias and motor fluctuations, as well as the development of dopamine-unresponsive features of gait making PD incurable to date (Müller \& Möhr, 2018).

Silymarin is flavonolignan, obtained from seeds of Silybum marianum. It is an antioxidant, hepatoprotective, antidiabetic, anti-inflammatory, antifibrotic, and cytoprotective (Vivekanandan et al., 2018). Neuroprotective effects of silymarin have been studied in various models of neurological disorders such as Alzheimer's disease and cerebral ischemia (Ullah \& Khan, 2018).

However, the mechanism of its neuroprotective effect is still unclear (Song et al., 2016). Moreover, less information is available about its effect on motor deficits in PD (Haddadi et al., 2014). Also, it is unknown whether it can protect dopaminergic neurons in the animal model of PD in vivo (Jung et al., 2014).

Thus, the aim of this work was to study the effect of different doses of Silymarin on rotenone-induced parkinsonism.

\section{Materials \& Methods:}

The current work was carried out at Medical Physiology Department, in accordance to the guidelines of the Ethical Committee of Medical Research, Faculty of Medicine, Tanta University, Egypt to minimize animal suffering.

\section{Reagents and drugs:}

All materials used, unless noted otherwise, were supplied by Sigma-Aldrich Co., USA. Serum oxidative DNA damage (8-hydroxy-2'-deoxyguanosine level) ELISA kit was supplied by (Enzo life Life sciences, USA). Malondialdehyde (MDA), Catalase (CAT) and niyrite/nitrate reagent kits were supplied by Bio-Diagnostics Co., Giza, Egypt. Rat Tumor necrosis factor alpha (TNF-) ELISA kit was supplied by (Shanghai Sunred Biological Technonlgy Co., China). Rat Brain derived neurotropic factor (BDNF) ELISA kit was supplied by MyBioSource Co.,USA. Caspase-3 reagent kits were supplied by RayBiotech, Inc.. Chemicals of high analytical grade were obtained from local chemical suppliers for measurement of dopamine level.

\section{Animal management:}

The present work was carried out on 60 adult male Albino rats of the local strain weighing (150-200 g). All rats were housed in isolated animal cages in room temperature in a standard animal house with free access to water and food all over the period of work. Animals were kept for two weeks for acclimatization.

\section{Experimental procedure (Figure 1):}

The rats were divided into three main groups as follows:

1. Control group (10 rats) which received no treatment,

2. Positive control group (10 rats) which received intraperitoneal (IP) injection of silymarin (SM) dissolved in $50 \%$ polyethylene glycol (PEG) at a dose of $200 \mathrm{mg} / \mathrm{kg}$ (Haddadi et al., 2014) daily for 2 weeks (Plangár et al., 2013).

3. Rotenone-treated (RT) group (40 rats): which received subcutaneous (SC) injection of rotenone at a dose of 1.5 $\mathrm{mg} / \mathrm{kg} / 48 \mathrm{~h}$ dissolved in 1:1 dimethylsulfoxide (DMSO) and PEG for 12 days (Soliman et al., 2016). This group was started with a larger number of rats because mortality was expected and to obtain the desired number of rats with parkinsonian features. Dead animals were excluded from the study. The remaining survived rats were subjected to preliminary behavioral tests after 3 days of training. From the rats that showed parkinsonian features, 40 rats only were used divided into 4 equal groups (10 rats each) for accurate statistical analysis; (IIIaRT group), (IIIb- $100 \mathrm{mg} / \mathrm{Kg}$ SM-RT), (IIIc- $200 \mathrm{mg} / \mathrm{Kg}$ SM-RT) and (IIId- $300 \mathrm{mg} / \mathrm{Kg}$ SM-RT) which 
received daily IP injection of silymarin at doses of 0, 100, 200 and $300 \mathrm{mg} / \mathrm{kg}$,dissolved in 50\% PEG, (Haddadi et al., 2014) respectively for 2 weeks (Plangár et al., 2013)

\section{Neurobehavioral Tests:}

At the end of the experiment, the following behavioral tests were carried out on all groups for neurobehavioral analysis of parkisnonian features. Rats were trained on these tests for three days, and then the tests were carried out: 1-Bar test for catalepsy: in which rats were placed with both forepaws on a bar which was $10 \mathrm{~cm}$ above the base in half rearing position and the time of removal of one or both paws was recorded and considered as the bar test elapsed time. Cut-off time for descent latency time was considered as $180 \mathrm{~s}$ (El-Horany et al., 2016).

2-Forepaw stride length to assess the shuffling gate observed in PD patients: In this test, rats were trained to walk down a narrow corridor which was lined by clean white paper. Their forepaws were dipped in ink and they were allowed to walk along the corridor again to analyze any deficits in stride length through measuring the distance between the footprints (Taylor et al., 2010).

\section{Blood and tissue collection:}

All rats were anaesthetized by i.p injection of phenobarbital (50 mg/kg) (Samson et al., 1957). Retro-orbital blood samples were collected from all animals for serum preparation. Then, all animals were sacrificed by cervical dislocation. Brains were dissected very quickly and carefully to avoid any mechanical trauma, washed with ice cold saline, and then divided into pieces, wrapped in aluminum foil and stored at $-80^{\circ} \mathrm{C}$ till used for preparation of brain tissue homogenate

The sacrificed animals were packed in special package according to safety precautions and infection control measures and sent with hospital biohazard.

\section{Biochemical analysis:}

Serum oxidative DNA damage (8-hydroxy-2'-deoxyguanosine level) was measured in all prepared sera of all groups (Rangel-López et al., 2013). The following parameters were measured in prepared brain tissue homogenate for all groups: Dopamine level: by fluorometric assay (Jacobowitz \& Richardson, 1978), MDA level: by colorimetric method (Ohkawa et al., 1979), CAT activity: by colorimetric method (Aebi, 1984), Nitrite/Nitrate level: by colorimetric method (Montgomery \& Dymock, 1961), Tumor Necrosis Factor Alpha (TNF- $\alpha$ ) assay: by ELISA (Brouckaert et al., 1993), Brain Derived Neurotrophic factor (BDNF) assay: by ELISA (Baker-Herman et al., 2004), Caspase-3 level: by ELISA (Porter \& Janicke, 1999).

\section{Statistical analysis:-}

Results were expressed as Mean \pm SD and all statistical comparisons were made by means of one-way ANOVA test, followed by Tukey's post hoc analysis, and p values less than 0.05 were considered statistically significant. Analysis was performed by statistical package for the social science software version 22.00 for windows (SPSS Inc., Chicago, IL, USA,2013) and GraphPad prism software version 7.0 (San Diego, USA, 2016).

\section{Results:-}

\section{Effect of silymarin on rotenone induced neurobehavioral deficits:}

As shown in figure 2 (A \& B) \& figure 3 (A,B,C \& D), the results of this work clearly indicate that rotenone could induce the characteristic motor parkinsonian features including catalepsy \& shuffling gate as shown by the significant change induced by rotenone in the bar test $\&$ the forepaw stride length tests respectively when compared to the control group. On the other hand, silymarin injection cause significant decrease in descent latency time in bar test and significant increase in forepaw stride length when compared to rotenone group. Silymarin effect was shown to be graded and dose-dependent as evidenced by the significant difference between the results of silymarin injection at a dose of $100 \mathrm{mg} / \mathrm{kg}$ and $300 \mathrm{mg} / \mathrm{kg}$ which eventually showed insignificant change when compared to the control.

\section{Effect of silymarin on rotenone induced oxidative, nitrostative and inflammatory stress:}

As shown in figure 4 (A \& B) \& figure 5 (A \&B), rotenone injection induced a significant increase of MDA levels in the brain tissue indicating increased lipid peroxidation, decreased catalase activity in the brain tissue indicating 
decreased antioxidant capacity, increased TNF- $\alpha$ indicating inflammatory stress and increased nitrite/nitrate in brain tissue indicating nitrosative stress. Silymarin injection showed significant change when compared to rotenonetreated groups in a dose dependant manner as aforementioned.

\section{Effect of silymarin on rotenone-induced apoptosis:}

As shown in figure 6, the results of this work showed that rotenone injection induced significant increase of brain tissue levels caspase-3 when compared to control respectively. Silymarin showed significant decrease of caspase-3 when compared to rotenone in a dose dependent manner. These levels showed insignificant change when compared to control at silymarin dose of $300 \mathrm{mg} / \mathrm{kg}$.

\section{Effect of silymarin on rotenone-induced DNA oxidative damage:}

As shown in figure 7, our results showed that rotenone causes significant oxidative DNA damage indicated by the significant increase in serum 8-OHdG levels when compared to control. Silymarin treatment resulted in significant decrease of $8-\mathrm{OHdG}$ levels when compared to rotenone reaching a result insignificant from control at the dose of $300 \mathrm{mg} / \mathrm{kg}$ in a dose dependent manner.

\section{Effect of silymarin on BDNF:}

As shown in figure 8, rotenone significantly lowered the BDNF level when compared to control. Silymarin, however could elevate the BDNF level significantly starting at a dose of $100 \mathrm{mg} / \mathrm{kg}$, which showed significant increase compared to rotenone results, in a dose-dependent manner as mentioned before. BDNF levels increased to reach an insignificant change when compared to control at doses of $200 \mathrm{mg} / \mathrm{kg}$ and $300 \mathrm{mg} / \mathrm{kg}$.

\section{Effect of silymarin on dopamine}

As shown in figure 9, rotenone also induced significant decrease in dopamine levels in brain tissue which was alleviated by silymarin starting at a dose of $200 \mathrm{mg} / \mathrm{kg}$ which showed significant increase when compared to rotenone and showed insignificant change when compared to control. The effect of silymarin showed a dosedependent manner as mentioned before.

\section{Discussion:-}

Behavioral assessment is a strong hallmark in evaluation of neuroprotection (Haddadi et al., 2014). The results of this work clearly indicate that rotenone could induce the characteristic motor parkinsonian features including catalepsy \& shuffling gate as shown by the results of the bar test \& the forepaw stride length tests respectively.

Consistent with our results, (Betarbet et al., 2000) showed that rotenone injection at a dose of 2-3 $\mathrm{mg} / \mathrm{kg}$ was able to induce the characteristic parkinsonian hypokinetic and postural instability features. However, lower doses have failed to induce these motor symptoms as investigated by (Cannon et al., 2009). Betarbet et al., 2000; Ayala et al., 2007 and Fathalla, et al., 2016 showed that rotenone caused most histopathological features of PD as much as damage to central dopaminergic neurons, clear degeneration and apoptosis of substantia nigra (SN) dopaminergic neurons along with the motor abnormalities. Dopamine loss in the striatum leads to reduced activation of striatal D1and D2-receptors, and subsequent reduction of activity along the direct (D1) pathway, an increase of activity along the indirect (D2) pathway, leading to an overall increase of the internal segment of globus pallidus / substatia nigra pars reticularis $(\mathrm{GPi} / \mathrm{SNr})$ activity and inhibition of thalamocortical transmission which, in turn, leads to akinesia and bradykinesia, respectively (Wichmann et al., 2018).

The results of (Haddadi et al., 2015) were similar to our results regarding catalepsy. All 3 doses of silymarin significantly attenuated the severity of induced catalepsy, indicated by bar test results, but $300 \mathrm{mg} / \mathrm{kg}$ showed an earlier response, after a single dose, than 200 and $100 \mathrm{mg} / \mathrm{kg}$. Moreover, (Haddadi et al., 2013) showed that pretreatment with silymarin in the same three doses was also capable of preventing catalepsy in 6-hydroxydopamine (6-OHDA) treated rats. Lu et al., 2010, Haddadi et al., 2013 and Haddadi, et al., 2014 attributed the silymarininduced improvement of cognitive deficits in PD animal models to silymarin's neuroprotective effect exerted through counteracting the oxidative stress process (Nencini et al., 2007) and inhibition of inflammatory pathways (Haddadi et al., 2013) which is also evidenced in this study. 
The results of this work revealed that rotenone injection induced a state of oxidative, inflammatory and nitrostative stress condition as evidenced by the significant increase of MDA, decreased catalase activity, increased TNF- $\alpha$ and increased nitrite/nitrate in brain tissue respectively. These effects were alleviated by silymarin injection.

rotenone has been suggested as an inhibitor of mitochondrial complex I activity uniformly throughout the brain (Xiong et al., 2009). Complex I inhibition causes generation of $\mathrm{OH}$ and ROS initially leading to depletion of antioxidant molecules such as glutathione in substantia nigra pars compacta (SNpc) (Saravanan et al., 2005). the enzymes that remove both $\mathrm{O} 2$ - and $\mathrm{H} 2 \mathrm{O} 2$ protect the cells against intermediates of oxygen generated during normal aerobic metabolism (Zelko et al., 2002). Impairment of catalase activity by rotenone, as evident in this study, hinders this antioxidant process. under neuropathological conditions, microglia are activated in response to dopaminergic neuronal damages. Additionally, activated microglia produce various potentially neurotoxic molecules, including iNOS and proinflammatory cytokines, such as TNF- $\alpha$ and IL-1b (Block \& Hong, 2005; Colton, et al., 2006 and Yu, et al., 2008). iNOS and pro-inflammatory cytokines may be involved in nigrostriatal dopaminergic neuronal death. Increasing evidence suggests that activated microglia generate ROS, resulting in oxidative stress to dopaminergic neurons in the SN (Jung et al., 2014).

Regarding the effect of silymarin on oxidative, inflammatory and nitrostative stress, there is no contradiction between our results and the results of (Haddadi, et al., 2013 and Haddadi, et al., 2014) who showed that pretreatment with silymarin prevented TNF- $\alpha$, other inflammatory cytokines and MDA elevation in nigrostriatal tissue of rat models of PD and in a doses-dependent pattern. Also, (Baluchnejadmojarad et al., 2010) showed significant decrease of MDA after single injection of SM at a dose of $200 \mathrm{mg} / \mathrm{kg}$ but not in the dose of $100 \mathrm{mg} / \mathrm{kg}$.

Controversially, Malekinejad et al., 2012 showed that unlike the lower dosage levels, long-term administration (8 weeks) of silymarin at a dose of $100 \mathrm{mg} / \mathrm{kg}$ might cause pro-oxidant effects on organs such as hippocampus which showed augmentation of NO and MDA content and upregulation of proinflammatory mediators such as IL-1b at mRNA level. This controversy might be attributed to the prolonged duration of administration. Also, (Johnson, et al., 2003) showed that SM at a dose of $250 \mathrm{mg} / \mathrm{kg}$ results in increased expression of TNF- $\alpha$, IL-1B, IL-6 and iNOS in mice spleenocytes. Also, in contradiction to our study, the results of (Baluchnejadmojarad et al., 2010) who showed that nitrate/nitrite level was non-significantly lowered by silymarin at a dose of $200 \mathrm{mg} / \mathrm{kg}$ when compared to the PD group which may be attributed to the shorter duration of treatment. Also (Lee et al., 2015) reported that silibinin, the major active constituent of silymarin, had no clear modulatory effect on neuroinflammation suggesting that suggest that silibinin has a direct neuroprotective role rather than indirect effects via modulating neuroinflammation.

The results of this work also showed that rotenone injection induced apoptotic changes as evidenced by the significantly increased brain tissue levels caspase-3 whereas Silymarin showed an anti-apoptotic effect.

(Baluchnejadmojarad et al., 2010 and Huang et al., 2016) reported that oxidative stress also compromises mitochondrial oxidative phosphorylation which leads to decreased energy output and secondary cell death. The critical damage to mitochondria, enhanced ROS formation and provoked oxidative damage caused by rotenone exposure mediates rotenone-induced apoptosis. Inhibition of apoptosis by silymarin is dependent on inhibition of NF-kB activation (Manna, et al., 1999).

Our results also showed that rotenone causes significant oxidative DNA damage indicated by the significant increase in serum 8-OHdG levels while Silymarin treatment resulted in significant decrease of 8-OHdG levels. Rotenoneinduced mitochondrial dysfunction leads to increased oxidative stress as evident in the present study. Hence, the oxidative damage to lipids, proteins and DNA can be detected as in the reports by (Dias et al., 2013 and Hwang, 2013) who reported oxidative damage in lipids, proteins and DNA in brain tissue from PD patients.

Overall, in all three studies (Alam et al., 1997; Zhang et al., 1999 and Hegde, 2006), late stage PD cases were used, and therefore the increase in DNA damage was found in the remaining small fraction of surviving neurons (or perhaps glia), as it is likely that by this point, the vast majority of dopaminergic neurons have already degenerated. It is unclear whether DNA damage is responsible for neuronal loss or is an epiphenomenon of the disease in the surviving neurons or both. In addition, mtDNA damage was not investigated (Coppedè \& Migliore, 2015). 
To our knowledge, this is the first study to demonstrate the effect of silymarin on DNA oxidative damage in rotenone-induced PD. Our results show no contradiction with the work of (Di Cesare Mannelli et al., 2013) who reported that silibinin decreased oxidative DNA damage in oxiplatin-induced oxidative stress in nervous systemderived cellular models.

The results of this work revealed that rotenone significantly lowered the BDNF level whereas silymarin, however could elevate the BDNF level significantly. To our knowledge, this study was the first to report the effect of silymarin on BDNF in rotenone-induced rat model of PD. (Song et al., 2016) reported the reduced expression of BDNF and High-affinity tyrosine kinase beta (TrkB) induced by lipopolysaccharide-injection was reversed by silibinin-treatment in memory impairment rat model which correlates with our results. Also, (Jangra et al., 2015) reported that silibinin ameliorated the aluminum-induced decrease in BDNF in hippocampus.

The results of this work revealed that rotenone induced significant decrease in dopamine levels in brain tissue which was alleviated by silymarin starting at a dose of $200 \mathrm{mg} / \mathrm{kg}$ which showed significant increase when compared to rotenone and showed insignificant change when compared to control.

(Anusha et al., 2017) reported rotenone-induced loss of tyrosine hydroxylase (TH) positive neurons and decreased TH protein expression in the SNpc. Also, Siddiqui, et al., 2010 and Anusha, et al., 2017 reported decreased D2 receptor expression in rotenone induced neurotoxicity which accounts for the reported dopaminergic neuron loss and level of dopamine release in the striatum. In addition, increased oxidative stress due to mitochondrial compromise in PD model animals has been proposed to contribute to the degeneration of dopaminergic neurons (Marella et al., 2008). In the same context, Cicchetti et al., (2002) reported that rotenone-induced oxidative stress results in microglia activation which leads to neurotoxicity of dopaminergic neurons.

Regarding silymarin's efect on dopamine, (Perez et al., 2014) reported that silymarin protected dopaminergic neurons starting at a dose of $100 \mathrm{mg} / \mathrm{kg}$ proposing that this was possibly due to its antioxidant and anti-inflammatory properties. They also showed that silymarin alone had no effect on dopamine levels in control mice which is shown in this study as well. Controversially, Perez et al., 2014 highlighted that silymarin doses of 200 and $300 \mathrm{mg} / \mathrm{kg}$ showed less dopamine preserving effect when compared to doses of 50 and $100 \mathrm{mg} / \mathrm{kg}$ which was attributed to the pro-oxidant and pro-inflammatory effect of silymarin at high doses as previously reported by (Malekinejad et al., 2012).

\section{Conclusion:-}

We can conlcude that silymarin is a potent neuroprotective flavonoid via its antioxidant, anti-inflammatory and antiapoptotic effect which eventually enhanced dopamine level and the characteristic motor deficits of PD. The investigated neuroprotective effect was shown to be dose-dependent.

\section{Recommendations:}

Our data suggests that silymarin can be used as a promising adjuvant therapy in treatment of PD. However, further clinical trials are required with special reference to the dose in order to avoid any undesirable side effects of high dose.

\section{Disclaimer:}

The authors report no conflict of interest. This study was self-funded.

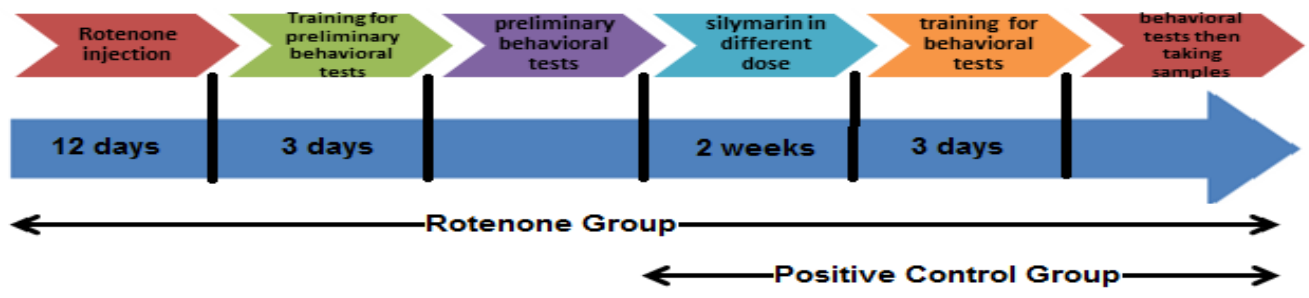

Figure 1:-Schematic diagram of the experimental procedure. 

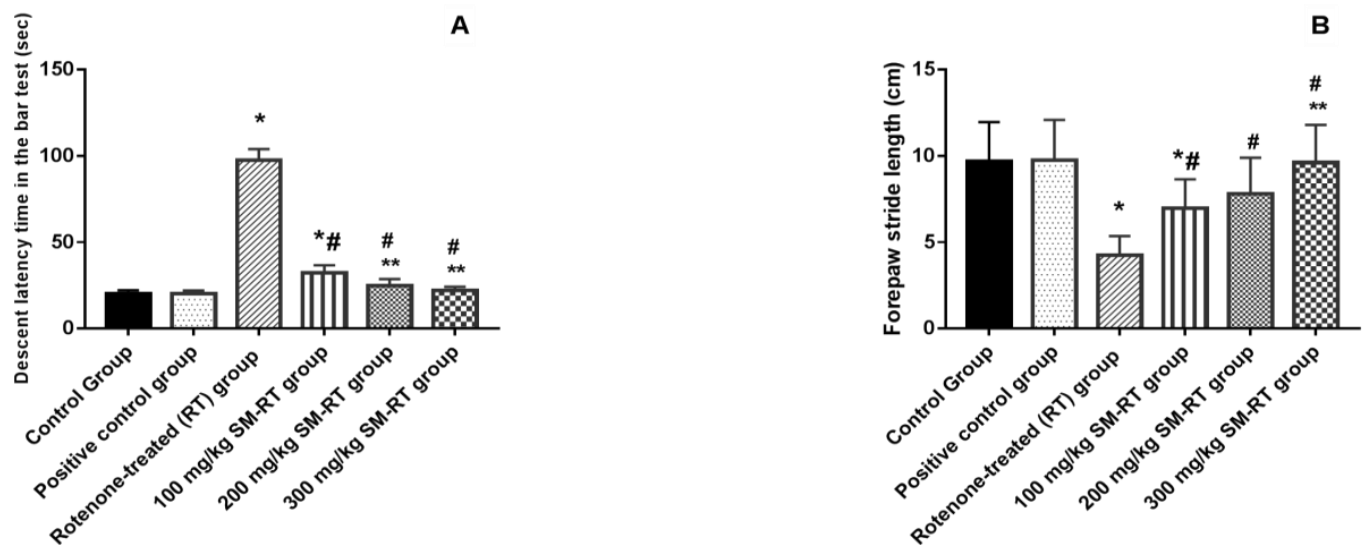

Figure 2 (A \& B):-Effect of different doses of SM on descent latency time in the bar test (seconds) (A) and Forepaw stride length $(\mathrm{cm})(\mathrm{B})$ in Rt-induced PD: Values are mean \pm SEM $(\mathrm{n}=10)$. *, \# and ** Denote a statistically significant difference at $\mathrm{p} \leq 0.05,{ }^{*}$ denotes statistical significance when compared to control group, \# denotes statistical significance when compared to Rotenone-treated group, ** denotes statistical significance when compared to $100 \mathrm{mg} / \mathrm{Kg}$ SM-RT group using one way ANOVA with Tukey post hoc

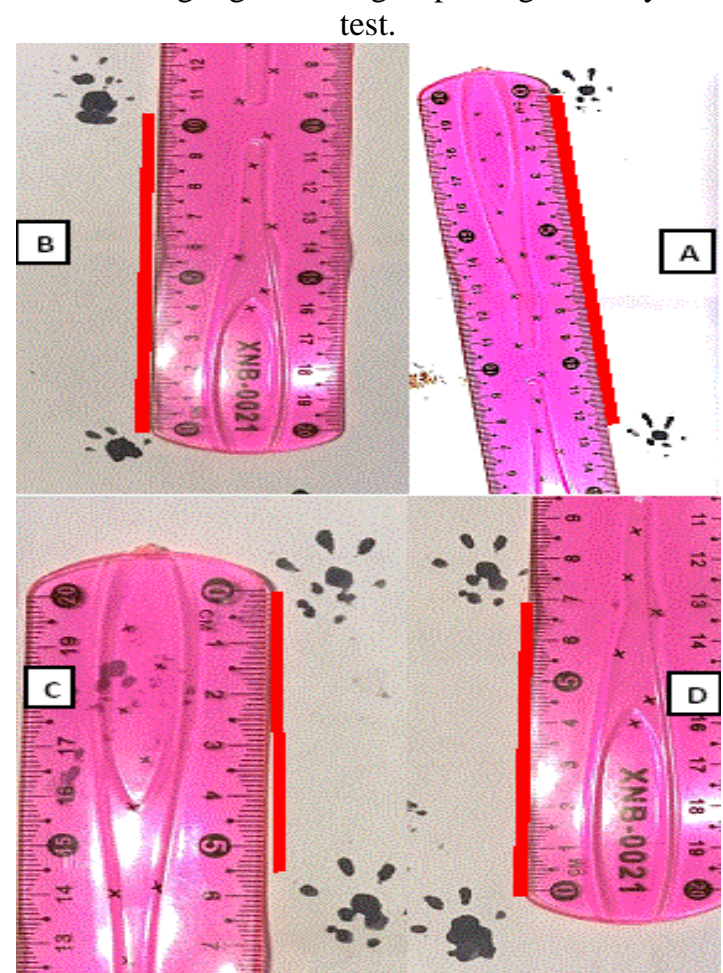

Figure 3:-(A, B, C and D): comparison of the forepaw stride length among the studied groups: A represents control group, B represents $300 \mathrm{mg} / \mathrm{kg}$ Silymarin-rotenone-treated group, C represents Rotenone-treated group and D represents $100 \mathrm{mg} / \mathrm{kg}$ Silymarin-rotenone-treated group 

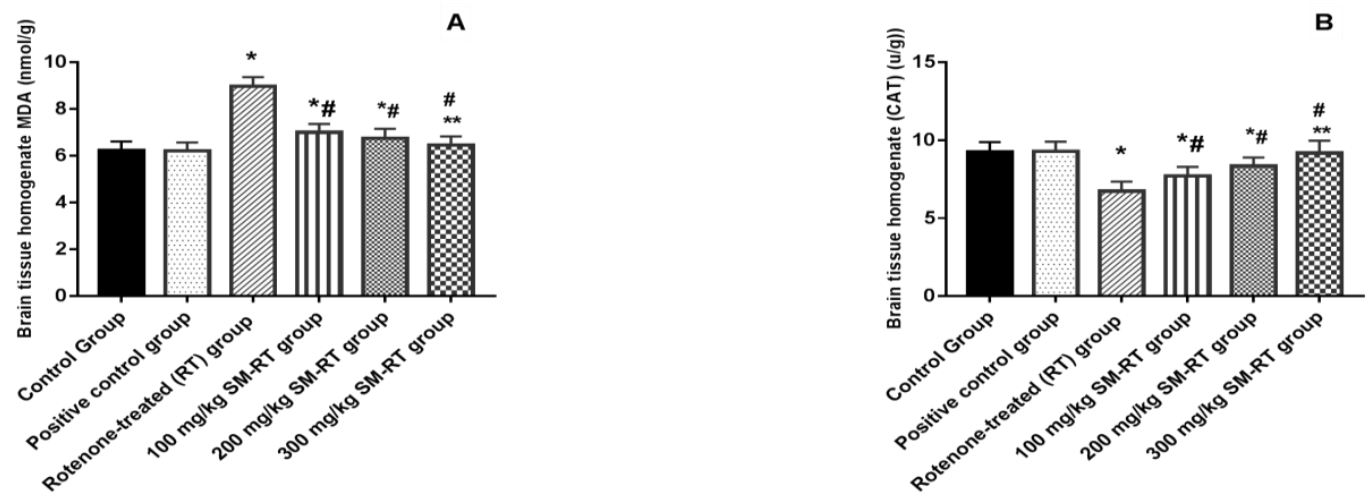

Figure 4 (A \& B):-Effect of different doses of SM on on brain tissue homogenate malondialdehyde (MDA) level (nmol/g) (A) and brain tissue homogenate catalase activity (CAT) (u/g) (B) in Rt-induced PD: Values are mean $\pm \operatorname{SEM}(\mathrm{n}=10) . *$, \# and $* *$ Denote a statistically significant difference at $\mathrm{p} \leq 0.05, *$ denotes statistical significance when compared to control group, \# denotes statistical significance when compared to Rotenone-treated group, ${ }^{* *}$ denotes statistical significance when compared to $100 \mathrm{mg} / \mathrm{Kg} \mathrm{SM}$ RT group using one way ANOVA with Tukey post hoc test
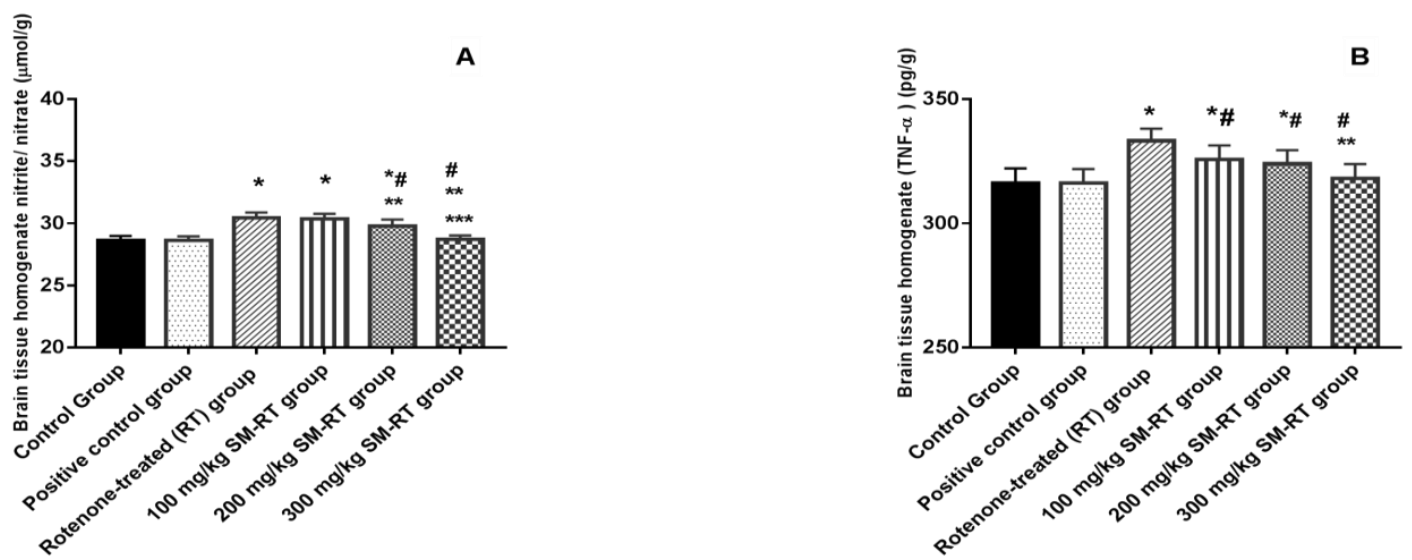

Figure 5 (A \& B):-Effect of different doses of SM on on brain tissue homogenate nitrite/ nitrate level $(\mu \mathrm{mol} / \mathrm{g})(\mathrm{A})$ and brain tissue homogenate tumor necrosis factor alpha level (TNF- $\alpha)(\mathrm{pg} / \mathrm{g})(\mathrm{B})$ in Rtinduced PD: Values are mean \pm SEM $(\mathrm{n}=10) . *, \#, * *$ and *** Denote a statistically significant difference at $\mathrm{p} \leq 0.05,{ }^{*}$ denotes statistical significance when compared to control group, \# denotes statistical significance when compared to Rotenone-treated group, $* *$ denotes statistical significance when compared to $100 \mathrm{mg} / \mathrm{Kg} \mathrm{SM}-\mathrm{RT}$ group, $* * *$ denotes statistical significance when compared to $200 \mathrm{mg} / \mathrm{Kg}$ SM-RT group using one way ANOVA with Tukey post hoc test 


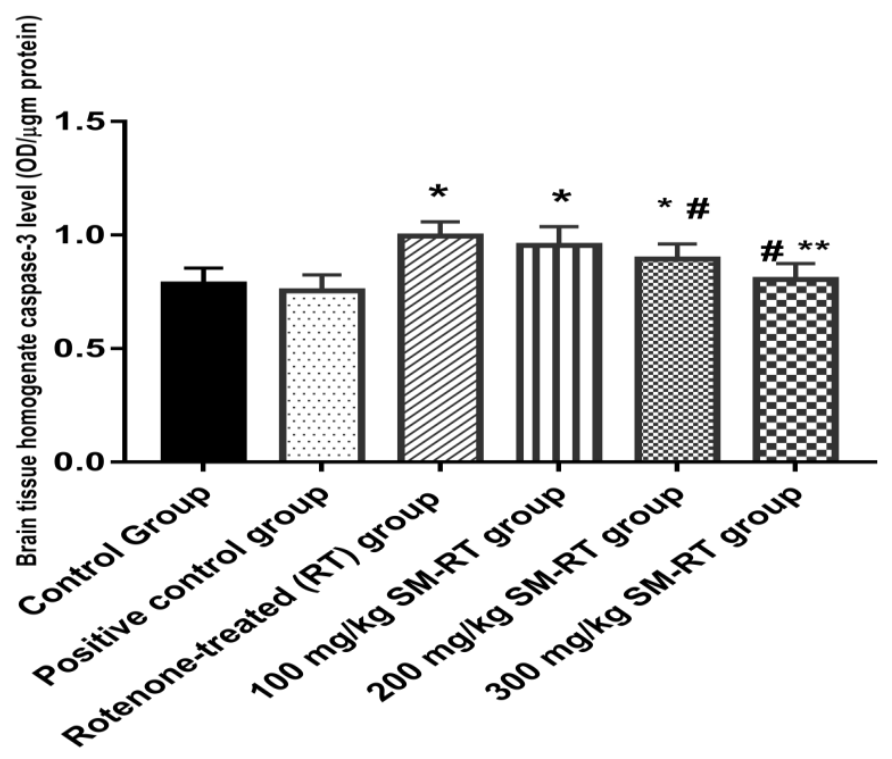

Figure 6:-Effect of different doses of SM on brain tissue homogenate caspase-3 level (OD/ $\mu$ gm protein) in Rt-induced PD: Values are mean \pm SEM $(\mathrm{n}=10)$. * \# and ** Denote a statistically significant difference at $\mathrm{p} \leq 0.05, *$ denotes statistical significance when compared to control group, \# denotes statistical significance when compared to Rotenone-treated group, $* *$ denotes statistical significance when compared to $100 \mathrm{mg} / \mathrm{Kg} \mathrm{SM-RT} \mathrm{group,} \mathrm{using} \mathrm{one} \mathrm{way} \mathrm{ANOVA} \mathrm{with} \mathrm{Tukey} \mathrm{post} \mathrm{hoc} \mathrm{test}$

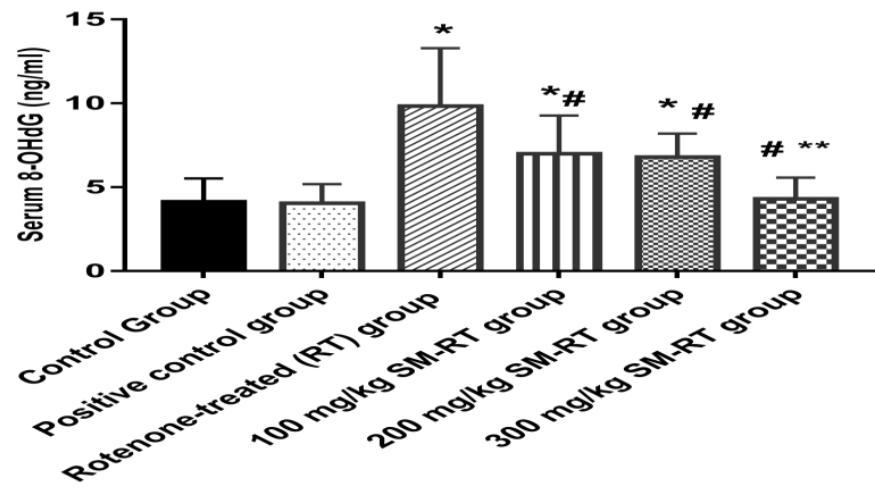

Figure 7:-Effect of different doses of SM on serum 8-hydroxy-2'-deoxyguanosine level (8-OHdG) $(\mathrm{ng} / \mathrm{ml})$ in Rt-induced PD: Values are mean \pm SEM $(\mathrm{n}=10)$. *, \# and ** Denote a statistically significant difference at $\mathrm{p} \leq 0.05, *$ denotes statistical significance when compared to control group, \# denotes statistical significance when compared to Rotenone-treated group, $* *$ denotes statistical significance when compared to $100 \mathrm{mg} / \mathrm{Kg}$ SM-RT group, using one way ANOVA with Tukey post hoc test 


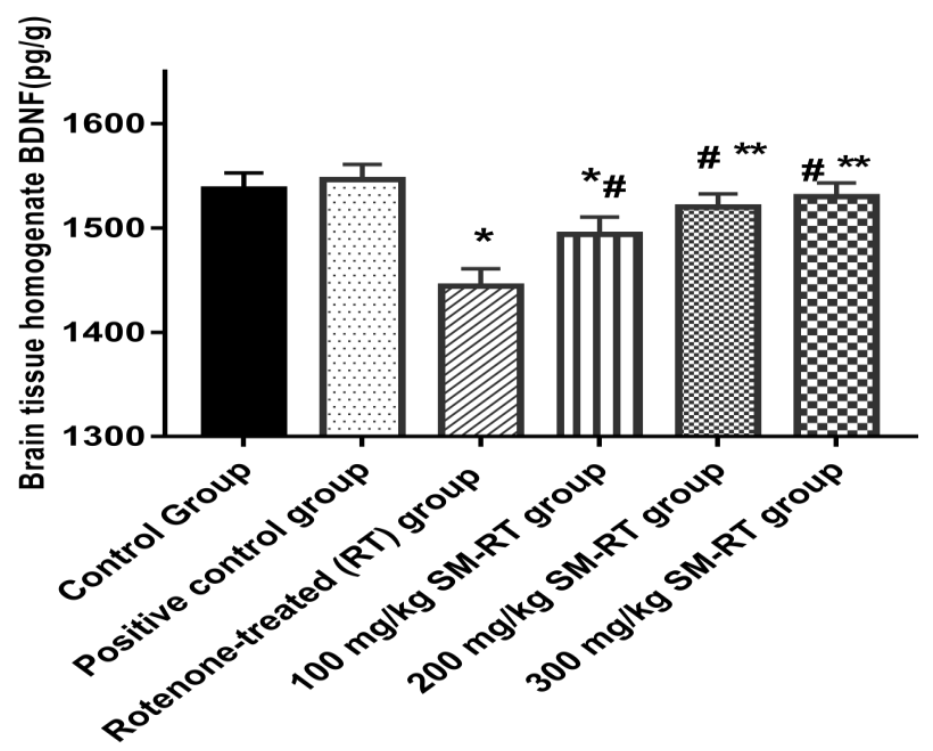

Figure 8:-Effect of different doses of SM on brain tissue homogenate brain derived neurotrophic factor $(\mathrm{BDNF})(\mathrm{pg} / \mathrm{g})$ in Rt-induced PD: Values are mean \pm SEM $(\mathrm{n}=10)$. *, \# and ** Denote a statistically significant difference at $\mathrm{p} \leq 0.05, *$ denotes statistical significance when compared to control group, \# denotes statistical significance when compared to Rotenone-treated group, ** denotes statistical significance when compared to $100 \mathrm{mg} / \mathrm{Kg}$ SM-RT group, using one way ANOVA with Tukey post hoc test

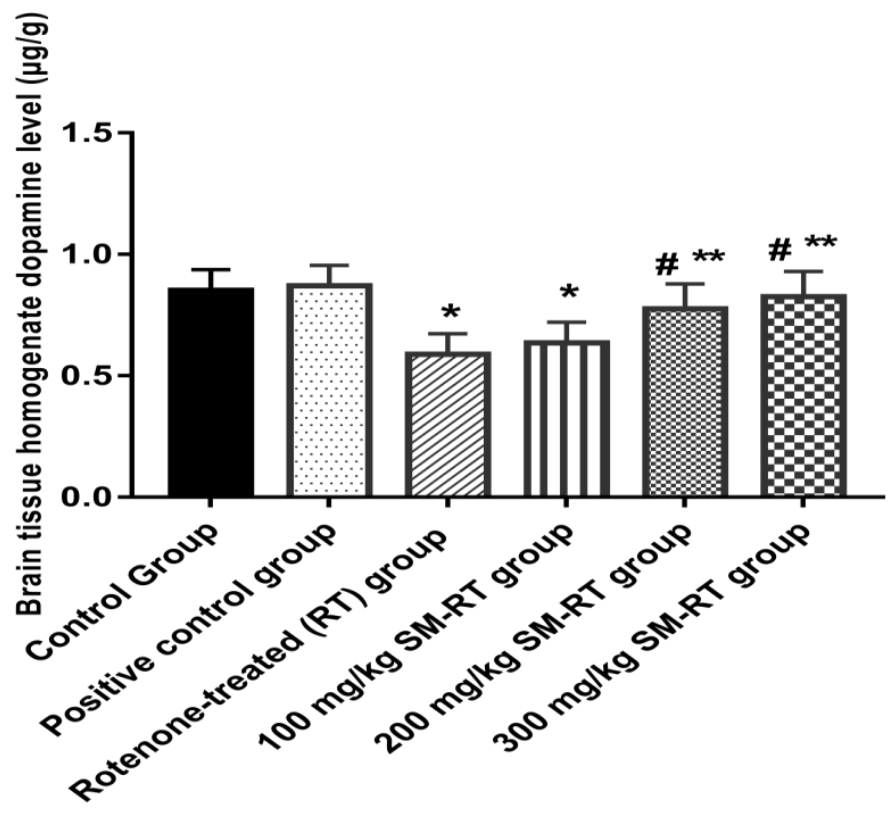

Figure 9:-Effect of different doses of SM on brain tissue homogenate dopamine level $(\mu \mathrm{g} / \mathrm{g})$ in Rt-induced PD: Values are mean $\pm \operatorname{SEM}(n=10) . *, \#$ and $* *$ Denote a statistically significant difference at $\mathrm{p} \leq 0.05, *$ denotes statistical significance when compared to control group, \# denotes statistical significance when compared to Rotenone-treated group, ** denotes statistical significance when compared to $100 \mathrm{mg} / \mathrm{Kg} \mathrm{SM}$ -

RT group, using one way ANOVA with Tukey post hoc test 


\section{References:-}

1. Aebi, H., 1984. Catalase in vitro. Methods Enzymol, Volume 105, 121-126.

2. Alam, Z., Jenner, A., Daniel, S.E., Lees, A.J., Cairns, N., Marsden, C.D. et al., 1997. Oxidative DNA damage in the parkinsonian brain: an apparent selective increase in 8-hydroxyguanine levels in substantia nigra. J Neurochem, 69(3):1196-1203.

3. Anusha, C., Sumathi, T. \& Joseph, L., 2017. Protective role of apigenin on rotenone induced rat model of Parkinson's disease: Suppression of neuroinflammation and oxidative stress mediated apoptosis. Chem Biol Interact, 269: 67-79.

4. Ayala, A., Venero, J. \& Cano, J., 2007. Mitochondrial toxins and neurodegenerative diseases. Front Biosci, 12:986-1007.

5. Baker-Herman, T., Fuller, D.D., Bavis, R.W., Zabka, A.G., Golder, F.J., Doperalski, N.J. et al., 2004. BDNF is necessary and sufficient for spinal respiratory plasticity following intermittent hypoxia. Nature Neurosci, 7(1): 48-55.

6. Baluchnejadmojarad, T., Roghani, M. \& Mafakheri, M., 2010. Neuroprotective effect of Silymarin in 6hydroxydopamine hemi-parkinsonian rat: involvemwnt of estrogen receptors and oxidative stress. Neuroscience Letters, 480:206-210.

7. Betarbet, R., Sherer, T.B., MacKenzie, G., Garcia-Osuna, M., Panov, A.V. \& Greenamyre, J.T., 2000. Chronic systemic pesticide exposure reproduces features of Parkinson's disease. Nat Neurosci, 3(12):13011306.

8. Block, M. \& Hong, J., 2005. Microglia and inflammation-mediated neurodegeneration: multiple triggers with a common mechanism. Prog Neurobiol, 76:77-98.

9. Brouckaert, P., Libert, C., Everaerdt, B., Takahashi, N., Cauwels, A. \& Fiers, W., 1993. Tumor necrosis factor, its receptors and the connection with interleukin 1 and interleukin 6. immunobiol, 187(3-5):317-329.

10.Cannon, J., Tapias, V., Na, H.M., Honick, A.S., Drolet, R.E. \& Greenamyre, J.T., 2009. A highly reproducible rotenone model of Parkinson's disease. Neurobiol Dis, 34(2):279-290.

11. Cicchetti, F., Brownell, A.L., Williams, K., Chen, Y.I., Livni, E. \& Isacson, O., 2002. Neuroinflammation of the nigrostriatal pathway during progressive 6-OHDA dopamine degeneration in rats monitored by immunohistochemistry and PET imaging. Eur J Neurosci, 15(6):991-998.

12. Colton, C., Vitek, M.P., Wink, D.A., Xu, Q., Cantillana, V., Previti, M.L. et al., 2006. NO synthase 2 (NOS2) deletion promotes multiple pathologies in a mouse model of Alzheimer's disease. Proc Natl Acad Sci USA, 103:12867-12872.

13. Coppedè, F. \& Migliore, L., 2015. DNA damage in neurodegenerative diseases. Mutat. Res, 776:84-97.

14. Di Cesare Mannelli, L., Zanardelli, M., Failli, P. \& Ghelardini, C., 2013. Oxaliplatin-induced oxidative stress in nervous system-derived cellular models: could it correlate with in vivo neuropathy? Free Radic Biol Med, 61:143-150.

15.Dias, V., Junn, E. \& Mouradian, M., 2013. The role of oxidative stress in Parkinson's disease. J Parkinsons Dis, Volume 3, pp. 461-491.

16.El-Horany, H., El-Latif, R., ElBatsh, M. \& Emam, M., 2016. Ameliorative Effect of Quercetin on Neurochemical and Behavioral Deficits in Rotenone Rat Model of Parkinson's Disease: Modulating Autophagy (Quercetin on Experimental Parkinson's Disease). J Biochem Mol Toxicol., 30(7):360-369.

17. Fathalla, A., Soliman, A., Hammdi, M. \& Moustafa, A., 2016. Adenosine A2A receptor blockade prevents rotenone-induced Motor Impairment in a Rat Model of Parkinsonism. Front Behav Neurosci, 10:28-35.

18. Haddadi, R., Eyvari Brooshghalan, S., Farajniya, S., Mohajjel Nayebi, A. \& Sharifi, H., 2015. Short-Term Treatment with Silymarin Improved 6-OHDA-Induced Catalepsy and Motor Imbalance in Hemi-Parkisonian Rats. Adv Pharm Bull., 5(4):463-469.

19. Haddadi, R., Mohajjel Nayebi, A. \& Brooshghalan, S., 2013. Pre-treatment with silymarin reduces brain myeloperoxidase activity and inflammatory cytokines in 6-OHDA hemi-parkinsonian rats. Neurosci Lett, 555: 106-111.

20.Haddadi, R., Nayebi, A.M., Farajniya, S., Brooshghalan, S.E. \& Sharifi, H., 2014. Silymarin improved 6OHDA-induced motor impairment in hemi-parkisonian rats: behavioral and molecular study. DARU Journal of Pharmaceutical Sciences, 22(1):38-49.

21. Hegde, M., 2006. Studies on genomic DNA topology and stability in brain regions of Parkinson's disease. Arch Biochem Biophys, 449(2):143-156. 
22.Huang, J.Y., Yuan, Y.H., Yan, J.Q., Wang, Y.N., Chu, S.F., Zhu, C.G. et al., 2016. 20C, a bibenzyl compound isolated from Gastrodia elata, protects PC12 cells against rotenone-induced apoptosis via activation of the Nrf2/ARE/HO-1 signaling pathway. Acta Pharmacol Sin, 37(6):731-740.

23. Hwang, O., 2013. Role of oxidative stress in Parkinson's disease. Exp. Neurobiol, 22:11-17.

24. Jacobowitz, D. \& Richardson, J., 1978. Method for the rapid determination of norepinephrine, dopamine, and serotonin in the same brain region. Pharmacol Biochem Behav, 8(5):515-519.

25.Jangra, A., Kasbe, P., Pandey, S.N., Dwivedi, S., Gurjar, S.S., Kwatra, M. et al., 2015. Hesperidin and Silibinin Ameliorate Aluminum-Induced Neurotoxicity: Modulation of Antioxidants and Inflammatory Cytokines Level in Mice Hippocampus. Biol Trace Elem Res, 168(2):462-471.

26. Johnson, V., He, Q., Osuchowski, M. \& Sharma, R., 2003. Physiological responses of a natural antioxidant flavonoid mixture, silymarin, in BALB/c mice: III. Silymarin inhibits T-lymphocyte function at low doses but stimulates inflammatory processes at high doses. Planta Med, 69(1):44-49.

27.Jung, U., Jeon, M., Choi, M. \& Kim, S., 2014. Silibinin Attenuates MPP1-Induced Neurotoxicity in the Substantia Nigra In Vivo. J Med Food, 17(5):599-605.

28.Lee, Y., Park, H., Chun, H. \& Lee, J., 2015. Silibinin Prevents Dopaminergic Neuronal Loss in a Mouse Model of Parkinson's Disease Via Mitochondrial Stabilization. J Neurosci Res. 93(5):755-765.

29.Lu, P., Mamiya, T., Lu, L., Mouri, A., Niwa, M., Kim, H.C. et al., 2010. Silibinin attenuates cognitive deficits and decreases of dopamine and serotonin induced by repeated methamphetamine treatment. Behav Brain Res, 207:387-393.

30. Malekinejad, H., Rahmani, F., Valivande-Azar, S., Taheri-Broujerdi, M. \& Bazargani-Gilani, B., 2012. Long-term administration of Silymarin augments proinflammatory mediators in the hippocampus of rats: evidence for antioxidant and pro-oxidant effects. Hum Exp Toxicol., 31(9):921-930.

31. Malekinejad, H., Rahmani, F., Valivande-Azar, S., Taheri-Broujerdi, M. \& Bazargani-Gilani, B., 2012. Long-term administration of Silymarin augments proinflammatory mediators in the hippocampus of rats: evidence for antioxidant and pro-oxidant effects. Hum Exp Toxicol., 31(9):921-930.

32. Manna, S., Mukhopadhyay, A., Van, N. \& Aggarwal, B., 1999. Silymarin suppresses TNF-induced activation of NF-kappa B, c-Jun N-terminal kinase, and apoptosis. J Immunol, 163(12): 6800-6809.

33. Marella, M., Seo, B.B., Nakamaru-Ogiso, E., Greenamyre, J.T., Matsuno-Yagi, A. \& Yagi, T.1., 2008. Protection by the NDI1 gene against neurodegeneration in a rotenone rat model of Parkinson's disease. PLoS One, 3(1):1433-1439.

34. Montgomery, H. \& Dymock, J., 1961. Colorimetric determination of nitric oxide. In Analyst, 86:414-416.

35. Müller, T. \& Kohlhepp, W., 2016. Hypomethylation in Parkinson's disease: an epigenetic drug effect? Mov Disord, 31(4):605-607.

36. Müller, T. \& Möhr, J.D., 2018. Long-term management of Parkinson's disease using levodopa combinations. Expert Opin on Pharmacother, 19(9):1003-1011.

37. Nencini, C., Giorgi, G. \& Micheli, I., 2007. Protective effect of silymarin on oxidative stress in rat brains. Phytomedicine, 14:129-135.

38. Ohkawa, H., Ohishi, N. \& Yagi, K., 1979. Assay for lipid peroxides in animal tissues by thiobarbituric acid reaction. Anal Biochem, 95(2)351-358.

39.Perez, H.J., Carrillo, S.C., Garcia, E., Ruiz-Mar, G., Perez-Tamayo, R. \& Chavarria, A., 2014. Neuroprotective effect of silymarin in an MPTP mouse model of Parkinson's disease. Toxicology, 319:3843.

40.Plangár, I., Zádori, D., Szalárdy, L., Vécsei, L. \& Klivényi, P., 2013. Assessment of the role of multidrug resistance-associated proteins in MPTP neurotoxicity in mice. Ideggyogy $S z, 66(11-12): 407-414$.

41.Porter, A. \& Janicke, R., 1999. Emerging role of caspase-3 in apoptosis. Cell Death Differ, 6(2):99-104.

42. Rangel-López, A., Paniagua-Medina, M.E., Urbán-Reyes, M., Cortes-Arredondo, M., Alvarez-Aguilar, C., López-Meza, J. et al., 2013. Genetic damage in patients with chronic kidney disease, peritoneal dialysis and haemodialysis: a comparative study. Mutagenesis, 28(2): 219-225.

43. Robert, C., Wilson, C.S., Lipton, R.B. \& Arreto C.D., 2018. Parkinson's disease: Evolution of the scientific literature from 1983 to 2017 by countries and journals. Parkinsonism Relat Disord, 8020(18):30495-30504.

44. Samson F., Colip F. \& Patterson J. (1957). Procedure for the Use of Sodium Pentobarbital (Nembutal@) Anesthesia in Classroom Experiments with Rats. Transactions of the Kansas Academy of Science, (1903), 425-428. 
45.Saravanan, K., Sindhu, K. \& Mohanakumar, K., 2005. Acute intranigral infusion of rotenone in rats causes progressive biochemical lesions in the striatum similar to Parkinson's disease. Brain Res, 1049(2):147-155.

46. Serrano-García, N., Fernández-Valverde, F., Luis-Garcia, E. R., Granados-Rojas, L., Juárez-Zepeda, T. E., Orozco-Suárez, S. A. et al., 2018. Docosahexaenoic acid protection in a rotenone induced Parkinson's model: Prevention of tubulin and synaptophysin loss, but no association with mitochondrial function. Neurochem Int, 121:26-37.

47.Siddiqui, M.A., Kashyap, M.P., Khanna, V.K., Yadav, S., Al-Khedhairy, A.A., Musarrat, J. et al., 2010. Association of dopamine DA-D2 receptor in rotenone-induced cytotoxicity in PC12 cells. Toxicol Ind Health, 26(8):533-542.

48. Soliman, A., Fathalla, A. \& Moustafa, A., 2016. Dose-dependent neuroprotective effect of caffeine on a rotenone-induced rat model of parkinsonism: A histological study. Neurosci Lett, 3940(16):30279-30288.

49.Song, X., Zhou, B., Zhang, P., Lei, D., Wang, Y., Yao, G. et al., 2016. Protective Effect of Silibinin on Learning and Memory Impairment in LPS-Treated Rats via ROS-BDNF-TrkB Pathway. Neurochem Res, 41(7):1662-72.

50. Taylor, T., Greene, J. \& Miller, G., 2010. Behaviouralphenotyping of mouse models of Parkinson's disease. Behav Brain Res, 211(1):1-10.

51. Ullah, H. \& Khan, H., 2018. Anti-Parkinson Potential of Silymarin: Mechanistic Insight and Therapeutic Standing. Front Pharmacol., 9:422-4329.

52. Vivekanandan, L., Sheik, H., Singaravel, S. \& Thangavel, S., 2018. Ameliorative effect of silymarin against linezolid-induced hepatotoxicity in methicillin-resistant Staphylococcus aureus (MRSA) infected Wistar rats. Biomed Pharmacother, 108:1303-1312.

53.Wichmann, T., Bergman, H. \& DeLong, M. R., 2018. Basal ganglia, movement disorders and deep brain stimulation: advances made through non-human primate research. J Neural Transm. 125(3):419-430.

54.Xiong, N., Huang, J., Zhang, Z., Zhang, Z., Xiong, J., Liu, X. et al., 2009. Stereotaxical Infusion of Rotenone: A Reliable Rodent Model for Parkinson's Disease. PLoS ONE, 4(11):e7878.

55. Yu, H., Wu, F., Lin, S. \& Shen, L., 2008. Recombinant arginine dei- minase reduces inducible nitric oxide synthase iNOS-mediated neurotoxicity in a coculture of neurons and microglia. J Neurosci Res, 86:29632972.

56.Zelko, I., Mariani, T. \& Folz, R., 2002. Superoxide dismutase multigene family: a comparison of the CuZnSOD (SOD1), Mn-SOD (SOD2), and EC-SOD (SOD3) gene structures, evolution, and expression. Free Radic Biol Med, 33(3):337-349.

57.Zhang, J., Perry, G., Smith, M.A., Robertson, D., Olson, S.J., Graham, D.G. et al., 1999. Parkinson's disease is associated with oxidative damage to cytoplasmic DNA and RNA in substantia nigra neurons. Am $J$ Pathol, 154(5):1423-1429. 